\section{FRI0534 RADIOGRAPHIC OUTCOMES WERE ASSOCIATED WITH PAIN AND FUNCTION RESPONSES: POST-HOC ANALYSIS FROM A PHASE 2 STUDY OF A WNT PATHWAY INHIBITOR, SM04690, FOR KNEE OSTEOARTHRITIS TREATMENT}

C. Swearingen $^{1}$, J. Tambiah ${ }^{1}$, A. Gibofsky ${ }^{2}$, N. Lane ${ }^{3}$, T. McAlindon ${ }^{4}$, M. Hochberg ${ }^{5}$. 'Samumed, LLC, San Diego; ${ }^{2}$ Hospital for Special Surgery, New York, ${ }^{3}$ UC Davis Medical Center, Davis; ${ }^{4}$ Tufts Medical Center, Boston; ${ }^{5}$ University of Maryland School of Medicine, Baltimore, USA

Background: SM04690, a small molecule intra-articular (IA) Wnt pathway inhibitor is in development as a potential disease modifying knee osteoarthritis drug. A phase 2, 52 week, randomised controlled trial evaluated changes in Western Ontario and McMaster Universities Osteoarthritis Index (WOMAC) Pain and Function and medial joint space width (mJSW). It was hypothesised that observed $\mathrm{mJSW}$ increases led to WOMAC subscore responder improvements. To address this question, a concordance analysis was performed.

Objectives: To evaluate concordance, or level of agreement, between mJSW and WOMAC Pain and Function 'responders.'

Methods: Subjects with ACR-defined knee OA, Kellgren-Lawrence (KL) grades $2-3$, received $2 \mathrm{~mL}$ IA SM04690 $(0.03,0.07$, or $0.23 \mathrm{mg})$ or placebo (PBO) in the target (most painful) knee. WOMAC Pain [0-50] and Function [0-170] were assessed at Weeks $0,4,13,26,39$ and 52 and knee radiographs at Weeks 0,26 and 52. Baseline-adjusted logistic regression group analyses estimated concordance between mJSW change and pain and function changes for responders who achieved both WOMAC Pain and Function improvements of $>50 \%$ and $>20$ [scaled to 100] points. Receiver-operator characteristic $(\mathrm{ROC})$ curves were generated with area under curve (AUC) to estimate concordance (AUC >0.7='acceptable' and $>0.8=$ 'excellent' concordance ${ }^{1}$ ). ITT and two subgroups were analysed: 1) unilateral symptomatic knee OA (pre-specified: UNI) and 2) unilateral symptomatic knee OA without widespread pain or comorbid symptoms (Widespread Pain Index $\leq 4$ and Symptom Severity $\leq 2$, post-hoc: UNI-WP).

Results: 455 subjects were enrolled (mean age $60.3[ \pm 8.7]$ years, BMI 29.9 [ \pm 4.6$] \mathrm{kg} / \mathrm{m}^{2}, 268$ [58.9\%] female, 292 [64.2\%] KL Grade 3, 164 [36.0\%] UNI knee $\mathrm{OA})$

In the ITT, approximately $53 \%$ were responders across all groups. In UNI, 20 (56\%) $0.03 \mathrm{mg} ; 20$ (63\%) $0.07 \mathrm{mg} ; 23(64 \%) 0.23 \mathrm{mg}$ and 15 (47\%) PBO, and in UNI-WP, 15 (56\%) $0.03 \mathrm{mg} ; 16$ (62\%) $0.07 \mathrm{mg} ; 19$ (70\%) $0.23 \mathrm{mg}$ and $12(44 \%)$ PBO were responders. The $0.03 \mathrm{mg}$ (UNI, NS; UNI-WP, $p=0.047)$ and $0.07 \mathrm{mg}$ (UNI, $p=0.009$; UNI-WP, $p=0.013$ ) doses also demonstrated increased mJSW compared to $\mathrm{PBO}$ at Week 52.

In ITT, no treatment group achieved AUC $>0.7$ (figure 1). In UNI, the $0.07 \mathrm{mg}$ dose demonstrated 'acceptable' concordance between response and mJSW ( $A \cup C=0.783$ ). In UNI-WP, the $0.07 \mathrm{mg}$ dose showed 'excellent' concordance $(\mathrm{AUC}=0.825)$.
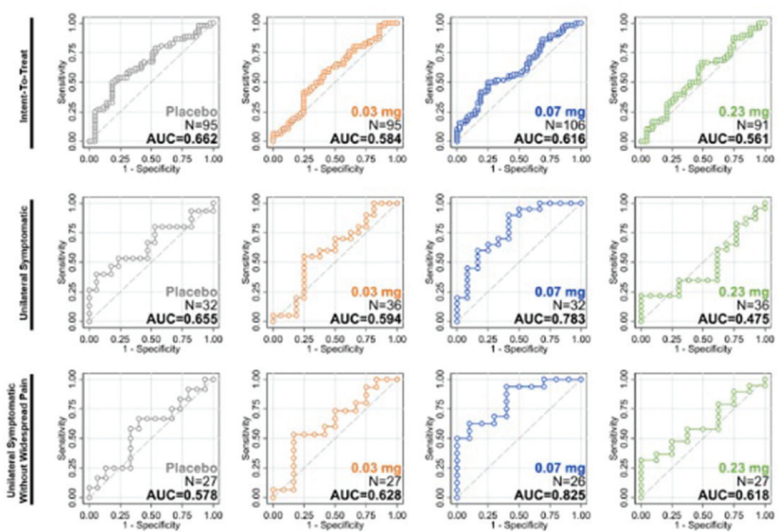

Abstract FRI0534 - Figure 1. ROC Curves Illustrating Concordance between WOMAC Pain and Function Response and mJSW Change by Treatment Group and Analysis Group

Conclusions: In this post-hoc analysis, treatment with SM04690 maintained or increased mJSW in the 0.03 and $0.07 \mathrm{mg}$ doses compared to PBO over 52 weeks. In UNI and UNI-WP 0.07 mg cohorts, changes in mJSW were concordant with WOMAC Pain and Function response.

\section{REFERENCE:}

[1] Hosmer DW, Lemeshow S. Applied Logistic Regression 2000. New York: John-Wiley \& Sons, Inc.
Disclosure of Interest: C. Swearingen Shareholder of: Samumed, LLC, Employee of: Samumed, LLC, J. Tambiah Shareholder of: Samumed, LLC, Employee of: Samumed, LLC, A. Gibofsky Shareholder of: AbbVie, Amgen, Johnson and Johnson, GSK, Regeneron, Consultant for: AbbVie, Pfizer, Horizon, Iroko, Celgene, Novartis/Sandoz, Samumed, LLC, Speakers bureau: AbbVie Celgene, Pfizer, N. Lane Consultant for: Samumed, LLC, T. McAlindon Grant research support from: Samumed, LLC, Consultant for: Samumed, LLC, Astellas, Flexion, Pfizer, Regeneron, Seikugaku, M. Hochberg Consultant for: Bioberica, EMD Serono, Novartis Pharma AG, Plexxikon, Pfizer, Proximagen, Regeneron, Samumed, LLC, Theralogix LLC

DOI: 10.1136/annrheumdis-2018-eular.6036

\section{FRI0535 THE CLINICAL AND RADIOGRAPHIC EARLY COURSE OF KNEE AND HIP OSTEOARTHRITIS OVER 10 YEARS IN CHECK (COHORT HIP AND COHORT KNEE)}

D. Schiphof ${ }^{1}$, J. Runhaar ${ }^{1}$, J. Waarsing ${ }^{2}$, W. van Spil ${ }^{3}$, M. van Middelkoop ${ }^{1}$, S. Bierma-Zeinstra ${ }^{4}{ }^{1}$ Department of General Practice; ${ }^{2}$ Department of Orthopeadics, ERASMUS MC, Rotterdam; ${ }^{3}$ Department of Rheumatology and Clinical Immunology, UMC Utrecht, Utrecht, ${ }^{4}$ Department of General Practice and Department of Orthopeadics, ERASMUS MC, Rotterdam, Netherlands

Background: Osteoarthritis $(\mathrm{OA})$ is the most prevalent joint disease and one of the leading causes of chronic pain and disability worldwide. Yet, relatively little is known about the early course of OA.

Objectives: To describe the clinical and radiological early course of hip and/or knee OA.

Methods: CHECK (Cohort Hip and Cohort Knee) is a multicenter, prospective observational cohort study of 1002 participants. Inclusion criteria were: 1) age 4565 years at the time of inclusion, 2) pain in knee(s) and/or hip(s), 3) never or not longer than 6 months ago for the first time consulted a physician for these symptoms. Participants were included through general practitioners and advertisements. Visits took place at baseline, and at 2, 5, 8, and 10 year follow-up (T0, T2, T5, T8 and T10). At each visit, questionnaires, including joint pain presence (Numeric rating score, NRS), morning stiffness, Western Ontario and McMaster Universities Osteoarthritis Index (WOMAC), were inquired, and physical examination, and $x$-ray imaging were performed. Clinical $O A$ was defined by the clinical American College of Rheumatism (ACR) criteria. Radiographic OA (ROA) was defined as Kellgren and Lawrence score ( $K$ and $L$ ) of $\geq 2$.

Results: 1002 participants (age 56 \pm 5 years (mean \pm sd); $79 \%$ female; BMI $26 \pm 4$ $\mathrm{kg} / \mathrm{m}^{2}$ ) were included. $83 \%$ reported knee pain at baseline, $59 \%$ reported hip pain, and $42 \%$ reported both. 10 year follow-up data were complete for $85 \%$ of the participants. The total WOMAC score showed a median of 21 (range $0-80$ ) at baseline and remained rather constant over time $(\mathrm{T} 2=20(0-83) ; \mathrm{T} 5=20(0-86) ; \mathrm{T} 8=19$ $(0-88) ; \mathrm{T} 10=19(0-81))$. The same was observed for pain (NRS). At baseline, 520 participants fulfilled the clinical ACR criteria for knee and/or hip OA. Of these, only $91(17.5 \%)$ participants subsequently fulfilled the ACR criteria at every follow-up visit. 138 participants did never fulfil the clinical ACR criteria for hip or knee OA. At baseline, 157 participants showed ROA in on or both knees and 161 participants showed ROA in on or both hips. After 10 years follow-up, 601 (60\%) participants had ROA in one or both knees and $513(51 \%)$ participants had hip ROA in one or both hips. Of those with hip OA in at least one hip, $256(50 \%)$ had bilateral knee ROA at T10. Of the participants with knee OA in at least one knee, $256(43 \%)$ had bilateral hip ROA at T10. Most joint replacements took place between 2 and 8 years follow-up (11 knees, 29 hips), predominantly in participants with multiple affected joints. Only $115(13.5 \%)$ participants did not develop ROA of knee or hip. Conclusions: Although mean pain scores remain fairly stable over time, individual scores tend to fluctuate over time. Therefore, only few participants constantly fulfil the clinical criteria for OA. More than half of the participants had ROA after 10 year follow-up and a large overlap of knee and hip ROA was observed. Numbers of joint replacements were highest in participants developing both hip and knee OA.

Disclosure of Interest: None declared

DOI: 10.1136/annrheumdis-2018-eular.5215

\section{FRI0536 PREGABALIN EFFICACY IN TREATMENT OF CHRONIC PAIN IN PATIENTS WITH KNEE OSTEOARTHRITIS}

E. Filatova, E. Turovskaya, L. Alekseeva. V.A. Nasonova Research Institute of Rheumatology, Moscow, Russia, Moscow, Russian Federation

Background: Modern methods of treatment of osteoarthritis have mainly antiinflammatory action. A few studies show the effectiveness of centrally acting drugs for chronic pain inosteoartritis (OA) of the knee.

Objectives: To study the efficacy of Pregabalin in treatment of chronic pain in patients with knee OA. 
Methods: The study involved 60 female patients with knee OA having neuropathic pain component (NPC; DN4 >4). Mean age 59.82 \pm 4.46 y (min 49, $\max 65$ years). All patients were randomly divided into two groups to be treated with 2 therapeutic regimens: aceclofenac +pregabalin (Group I) or aceclofenac (Group II) for 5 weeks (3 visits). All patients were subjected to clinical and neurological examination, total WOMAC score assessment, verification of neuropathic pain (NP) (questionnaire DN4 and Pain DETECT), and VAS pain intensity assessment at rest.

Results: The therapy was successful in both groups with respect to WOMAC score [figure 1] (Group I - 1385,30 $\pm 365,83$ vs $1034,70 \pm 402,37$ vs 886,64 $\pm 456,31$; Group II - 1206,04 $\pm 358,72$ vs $1016,45 \pm 428,52$ vs 976,55 $\pm 408,02$ respectively, $p=0.01$ ). Significant reduction of pain intensity at rest was

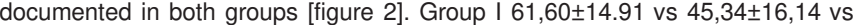
$36,24 \pm 18,09$; Group II $56,07 \pm 22,58$ vs $44.86 \pm 18.68$ and vs of $41.96 \pm$ of 24.04 , $\mathrm{p}=0.01$, respectively). Therapeutic regimens in both groups had positive impact on NPC based on DN4 questionnaire and Pain DETECT scores. However, a combination of a NSAID with anticonvulsants agent (pregabalin) resulted in a more pronounced effect. Changes in DN4 values in Group I (visit1/visit3) were: 5.97 $\pm 1,24 / 2,97 \pm 1,83 p=0.001$; and in Pain DETECT values $-17,93 \pm 3,87 / 9,34 \pm 6,18$, $\mathrm{p}=0.001$; while in Group II DN4 scores were 5,35 $\pm 0,93 / 3,79 \pm 2,29, \mathrm{p}=0.001$; and Pain DETECT - 15,03 $\pm 5,26 / 12,24 \pm 6,29 p=0.02$. [figures 3-4]

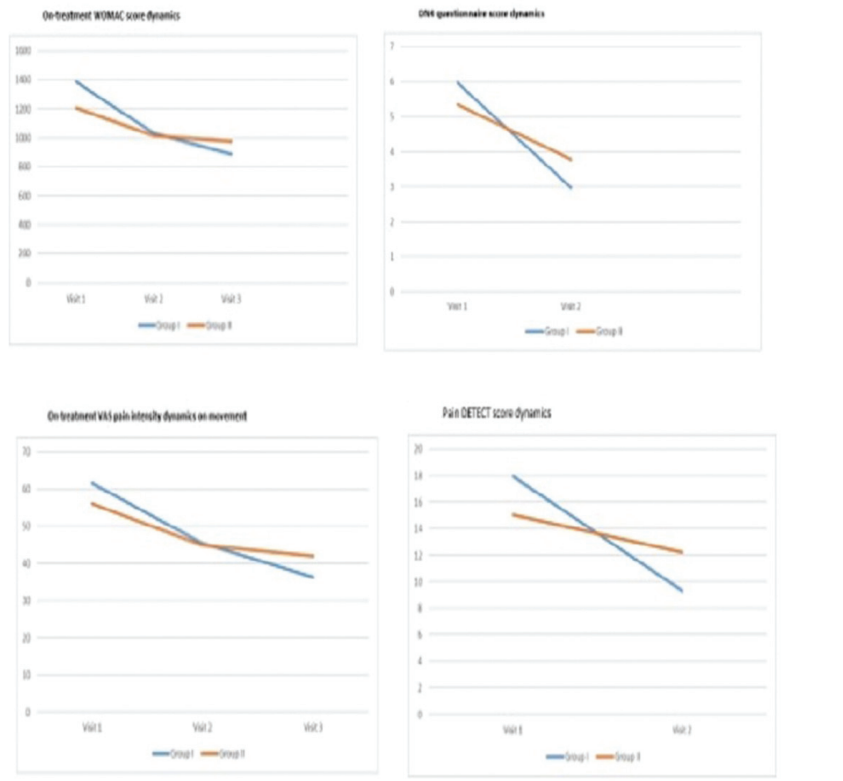

Conclusions: Complex therapy with the use of Pregabalin in patients with OA of the knee, with signs of NPC, allows not only effectively reduce pain intensity and improve functional activity of patients and, consequently, the quality of life.

Disclosure of Interest: None declared

DOI: 10.1136/annrheumdis-2018-eular.2377

\section{FRI0537 NEUROPHYSIOLOGICAL DATA IN PATIENTS WITH CHRONIC PAIN IN KNEE OSTEOARTHRITIS}

E. Turovskaia ${ }^{1}$, L. Alekseeva ${ }^{1}$, E. Filatova ${ }^{2}$, C. Chimienti ${ }^{3} .{ }^{1}$ laboratory of osteoarthritis, V.A. Nasonova Research Institute of Rheumatology; ${ }^{2}$ I.M. Sechenov First Moscow State Medical University, Moscow, Russian Federation; ${ }^{3}$ OOOF Senior's Homes Inc, Barrie, Canada

Background: Traditionally, chronic pain in OA is considered to be a classical model of nociceptive pain. Nociceptive mechanism can't explain the presence: referred pain, secondary hyperalgesia and other sensitive phenomena[. ${ }^{1}$ Recent studies has shown that besides nociceptive pain there is another mechanism that takes place in chronic pain OA -central sensitisation[. ${ }^{2}$ Expolore of chronic pain OA can be reached only by a complex approach in examining patients with chronic knee OA that includes not only a rheumatological examination, but examination of the neurological sphere and algometria. At the moment there are only few studies dedicated to neurophysiological changes in pain $\mathrm{OA}{ }^{3}$

Objectives: to assess pain system with neurophysiological examination in chronic pain $\mathrm{OA}$

Methods: 46 chronic knee pain $\mathrm{OA}$ and 23 healthy group control women, 45-65 years old, were included. The study included clinical rheumatologic, neurological examinations, neuropathic pain scales (DN4 and Pain DETECT). Knee X-ray and ultrasound studies. Neurophysiological examination included algometria with algometer and wind-up fenomena observed by Neuropen. Five test sites in the peripatellar region and one control site on tibialis anterior $(5 \mathrm{~cm}$ distal to the tibial tuberosity) were located and marked for examination

Results: Neuropathic pain scales demonstrated neuropathic descriptors present in OA patients. Neurological examination revealed no somatosensory deficit. But examination of the sensitive sphere indicated hyperalgesia: primary hyperalgesia (increased sensitivity to pain in the damaged joint) and secondary hyperalgesia. Algometria revealed low pressure pain threshold(PPT) above injured knee and intact region compared with healthy group. (tab.1) PPT in intact region was compared between OA patients and control group by ROC-analysis. Max of PPT in intact region in patient with OA was $-14,70$, $\min -1,80$, mean value $-7,34$. Mean value of PPT in contral group was 15,18. Area under curve was- 0888 . Sensitivity $-70 \%$. Specificity $-83 \%$. ROC-analysis demonstrasted that low PPT in OA patints is a specific feature of central sensitisation (figure 1) Wind-up fenomena examination in intact region revealed significant difference of data in OA patients with reffered pain and control group $(4,3 \pm 2,1$ vs $2,44 \pm 1,3 p=0,003)$ and $O A$ patients without reffered pain and control group $(3,67 \pm 1,43$ vs $2,44 \pm 1,3 p=0,011)$.

\begin{tabular}{lccc}
\hline $\begin{array}{l}\text { PPT } \\
\text { data }\end{array}$ & $\begin{array}{c}\text { OA patients } \\
\mathbf{n}=\mathbf{4 6}\end{array}$ & $\begin{array}{c}\text { Control group } \\
\mathbf{n = 2 3}\end{array}$ & $\mathbf{P}$ \\
\hline V1 & $7,04 \pm 2,92$ & $15,13 \pm 5,08$ & 0000 \\
V2 & $8,41 \pm 4,39$ & $14,86 \pm 4,5$ & 0001 \\
V3 & $7,75 \pm 3,45$ & $16,08 \pm 4,97$ & 0000 \\
V4 & $4,57 \pm 2,2$ & $11,27 \pm 4,98$ & 0000 \\
V5 & $4,41 \pm 2,1$ & $10,7 \pm 4,8$ & 0000 \\
V6 & $7,34 \pm 3,66$ & $15,18 \pm 5,07$ & 0000 \\
\hline
\end{tabular}

ROC Curve

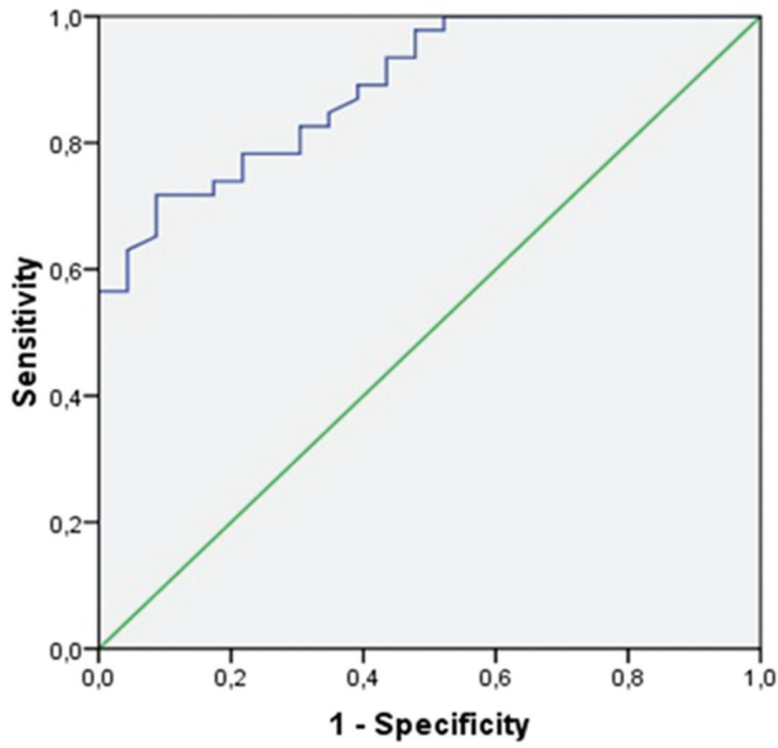

Diagonal segments are produced by ties.

Figure 1 Diagonal segments are produced by ties.

Conclusions: Chronic $O A$ is a complex of mechanisms and includes nociceptive and central sensitisation. Neurophysiological changes: low ppt in demaged area and even intact region and wind-up fenomena were revealed in all OA patients and charectrerises central sensitisation. Mechanism-oriented treatment should also target CNS, including anticonvulsant, and antidepressant agents.

\section{REFERENCES:}

[1] Schaible HG, Ebersberger A, von Banchet GS. Mechanisms of pain in arthritis. Ann N Y Acad Sci 2002;966:343-54.

[2] Kosek E, Ordeberg G. Abnormalities of somatosensoryperception in patients with painful osteoarthritis normalize following successful treatment. Eur J Pain 2000;4:229-38

[3] Lars Arendt-Nielsen, HonglingNie, Mogens B Laursen. Sensitisation in patient with knee osteoarthritis. Pain 149 2010;573-581.

Disclosure of Interest: None declared

DOI: 10.1136/annrheumdis-2018-eular.1943 